\title{
C2-ceramide signaling in glioma cells: synergistic enhancement of CD95-mediated, caspase-dependent apoptosis
}

\author{
B Wagenknecht ${ }^{1}$, W Roth ${ }^{1}$, E Gulbins ${ }^{2}$, H Wolburg ${ }^{3}$ and \\ M Weller ${ }^{*, 1}$ \\ ${ }^{1}$ Laboratory of Molecular Neuro-Oncology, Department of Neurology, \\ University of Tübingen, Tübingen, Germany \\ 2 Department of Immunology, St. Jude Children's Research Hospital, Memphis, \\ TN, USA \\ 3 Institute of Pathology, University of Tübingen, Tübingen, Germany \\ * Corresponding author: M Weller, Department of Neurology, University of \\ Tübingen, School of Medicine, Hoppe-Seyler-Strasse 3, 72076 Tübingen, \\ Germany. Tel: 497071 2982141; Fax: 497071 295260; \\ E-mail: michael.weller@uni-tuebingen.de
}

Received 20.7.00; revised 22.1.01; accepted 29.1.01

Edited by BA Osborne

\begin{abstract}
Most human malignant glioma cell lines are susceptible to CD95 ligand (CD95L)-induced apoptosis. Here, we report that glioma cells are also susceptible to the cytotoxic effects of exogenous C2-ceramide. This form of cell death exhibits some morphological features of apoptosis as assessed by electron microscopy, but is unaffected by the broad spectrum caspase inhibitor, zVAD-fmk. Further, CD95L-induced apoptosis is synergistically enhanced by coexposure of the glioma cells to CD95L and C2-ceramide. CD95L-induced caspase 3-like activity, cytochrome $c$ release and cleavage of caspases 3 , 8, 9 and poly(ADP-ribose)polymerase (PARP) increase substantially after cotreatment with CD95L and C2-ceramide compared with CD95L treatment alone. None of these events occur in response to cytotoxic concentrations of C2-ceramide alone. C2-ceramide does not alter CD95 expression. Gene transfer-mediated enhancement of CD95 expression results not only in increased susceptibility to CD95L, but also in increased sensitivity to C2-ceramide. We conclude that (i) synergistic induction of apoptosis by C2-ceramide and CD95L depend on a cross-talk between the two signal transduction pathways and that (ii) C2-ceramide, independently of its sensitizing effects on CD95-dependent caspase activation, is also capable of triggering an apoptotic signaling cascade that is unaffected by zVAD-fmk-mediated caspase inhibition, but promoted by high levels of CD95 expression. Cell Death and Differentiation (2001) 8, 595-602.
\end{abstract}

Keywords: ceramide; CD95 (APO-1, Fas); glioma; apoptosis; caspases

Abbreviations: Ac-DEVD-amc, acetyl-DEVD-aminomethyl coumarin; zVAD-FMK, benzoyl-VAD-fluoromethylketone; TCA, trichloracetic acid; CD95L, CD95 ligand; PBS, phosphate-buffered saline; DAPI, 4'6-diamidine-2'-phenylindole dihydrochloride; TNF, tumornecrosis factor; DISC, death inducing signaling complex; RIP receptor-interacting protein; AIF, apoptosis-inducing factor; JNK, Jun-N-terminal kinase

\section{Introduction}

Ceramide, a sphingosine-based lipid, is produced in cells upon hydrolysis of sphingomyelin or by de novo synthesis. ${ }^{1}$ The hydrolysis of sphingomyelin occurs via the catalytic action of two enzymes, neutral and acidic sphingomyelinase. Cytokines such as tumor necrosis factor (TNF), corticosteroids such as dexamethasone or ionizing radiation activate sphingomyelinases in certain cell types. ${ }^{2-4}$ Moreover, numerous studies have described intracellular ceramide accumulation upon triggering of apoptotic death signaling, e.g., during activation of the death receptor, CD95., 2,5-9 It has been suggested that endogenous ceramide activates stress-activated protein kinases/Jun-Nterminal kinase (SAPK/JNK) and the Ras/Raf1-signaling pathway, resulting in the activation of phospholipase $A_{2}$ and the synthesis of arachidonic acid. ${ }^{6,10-13}$ The involvement of ceramide-activated protein kinase (CAPK), ceramide-activated protein phosphatase (CAPP) and, importantly, caspases in ceramide signaling has also been postulated. ${ }^{14-16}$

Short chain analogs of ceramide, in particular C2- and C6-ceramide, may mimic some of the signaling aspects of endogenous ceramide. However, since these analogs are water-soluble whereas endogenous ceramide is one of the most hydrophobic molecules in the cell, it is unlikely that these analogs match closely all biological effects of endogenous ceramide. In any case, C2-ceramide is an interesting tool to study apoptosis of tumor cells since C2ceramide efficiently triggers apoptosis in almost any cell.

The susceptibility of human malignant glioma cell lines to ceramide-induced apoptosis has been described. ${ }^{17,18}$ Similar to our previous data on CD95-mediated apoptosis $^{19}$ and to the work on C2-ceramide cytotoxicity reported here (Figure 1), T98G, U87MG and SF126 glioma cells, although resistant to radiation-induced apoptosis, were sensitive to C2-ceramide and to CD95-mediated apoptosis. ${ }^{18}$ In contrast to CD95-mediated apoptosis, C2ceramide-induced glioma cell death was inhibited by coexposure to an inhibitor of protein synthesis, cycloheximide. ${ }^{17}$ Conversely, both were inhibited by ectopic expression of the protooncogene product, bcl-2. ${ }^{17,20}$ Prompted by these findings, we sought to shed light on the mechanisms of C2-ceramide-induced glioma cell death and on a possible cross-talk between short chain ceramideand CD95-mediated apoptotic signaling. 
A

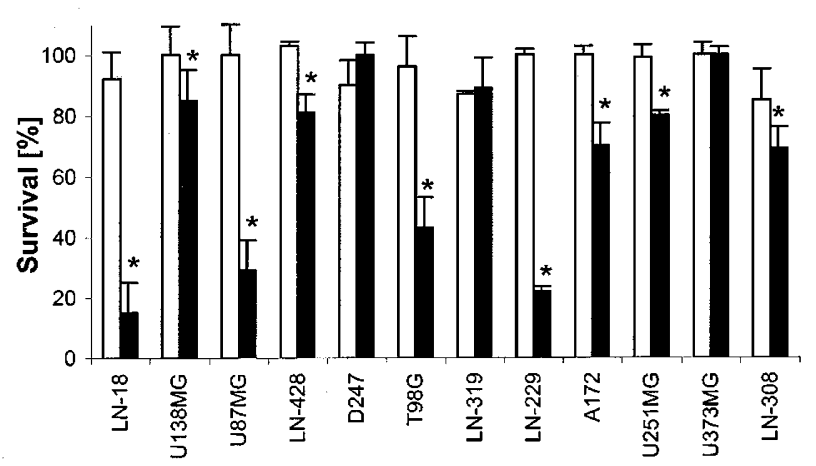

B

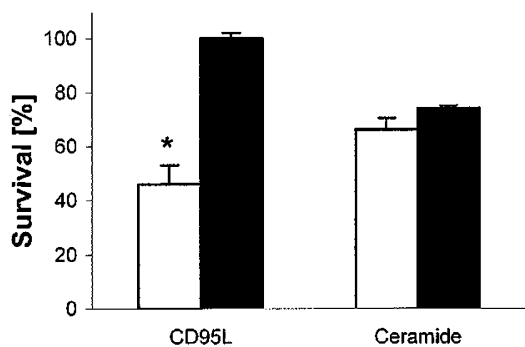

Figure 1 Cytotoxic activity of C2-ceramide in human malignant glioma cell lines. (A) Viability was assessed at $24 \mathrm{~h}$ after exposure to $\mathrm{C} 2$-ceramide at 17 or $50 \mu \mathrm{M}$ by crystal violet assay. Data are expressed as mean percentages and S.D. of survival ( $n=3,{ }^{*} P<0.05, t$-test). (B) Wild-type (wt) or CD95L-resistant (R) $\mathrm{LN}$-18 glioma cells were treated with CD95L $(30 \mathrm{U} / \mathrm{ml})$ or C2-ceramide $(50 \mu \mathrm{M})$ for $16 \mathrm{~h}\left({ }^{*} P<0.05, t\right.$-test $)$

\section{Results}

\section{Human malignant glioma cell lines are susceptible to C2-ceramide-induced cytotoxicity}

We examined the cytotoxic activity of C2-ceramide, a cell permeable synthetic analog of ceramide, ${ }^{8}$ in 12 human malignant glioma cell lines. Figure 1 shows percentages of survival after a $24 \mathrm{~h}$ treatment with C2-ceramide at 17 or $50 \mu \mathrm{M}$. All cell lines were resistant to ceramide at $17 \mu \mathrm{M}$. Exposure to $\mathrm{C} 2$-ceramide at $50 \mu \mathrm{M}$ disclosed that glioma cell lines are differentially susceptible to C2-ceramide-induced cell death. LN-18, U87MG, T98G and LN-229 cells were rather sensitive to $\mathrm{C} 2$-ceramide-induced cytotoxicity. In contrast, C2-ceramide at $50 \mu \mathrm{M}$ failed to significantly reduce the viability of D247, LN-319 and U373MG cells $(P>0.05, t$ test). The remaining cell lines exhibited moderate sensitivity to C2-ceramide. This panel of glioma cell lines has been previously characterized for sensitivity to cytotoxic cytokines such as CD95L or Apo2 ligand (Apo2L)/tumor necrosis factorrelated apoptosis-inducing ligand (TRAIL) ${ }^{21}$ and cancer chemotherapy drugs. ${ }^{22}$ Interestingly, a comparison of the susceptibility of glioma cells to ceramide and CD95L or Apo2L/TRAIL revealed a similar pattern of sensitivity. The cell lines most sensitive to C2-ceramide, LN-18, U87MG, T98G and LN-229, were also sensitive to CD95L and Apo2L/TRAIL.
Conversely, the ceramide-resistant cell lines were mostly cross-resistant to CD95L and Apo2L/TRAIL. A statistical analysis demonstrated a weak positive correlation between sensitivity to C2-ceramide $(50 \mu \mathrm{M})$ and CD95L $(100 \mathrm{U} / \mathrm{ml})$ ( $r=0.6, P<0.05)$ or Apo2L/TRAIL $(1 \mu \mathrm{g} / \mathrm{ml} ; r=0.6, P<0.05)$. In contrast, no interrelation for C2-ceramide sensitivity and sensitivity to various cancer chemotherapy drugs was apparent (data not shown). We have recently described a subline of LN-18 which is resistant to CD95L and Apo2L/ TRAIL presumably because of defective processing of proximal caspases, notably caspase $8 .^{23}$ These cells did not acquire cross-resistance to C2-ceramide cytotoxicity (Figure 1B).

Next, we performed electron microscopic studies to elucidate the mode of cell death caused by C2-ceramide. Compared with untreated LN-18 cells (Figure 2A), exposure to $\mathrm{C2}$-ceramide resulted in morphological alterations typical of apoptosis, e.g., membrane blebbing, strong cytoplasmic vacuolization with cellular rounding and condensation of chromatin (Figure 2B). However, the nuclear changes were less prominent than previously observed and confirmed here for CD95-mediated apoptosis (Figure 2D). The coexposure to C2-ceramide and CD95L or to CD95L alone produced a classical apoptotic phenotype (Figure $2 \mathrm{C}, \mathrm{D})$. That apoptotic nuclear changes were not prominent in cells treated with C2-ceramide only, was consistent with the observation that less than $10 \%$ of C2-ceramide-treated cells showed nuclear condensation by DAPI staining (data not shown).

\section{Synergistic enhancement of C2-ceramide- and CD95L-induced cell death}

To further characterize possible interactions of C2-ceramide- and CD95-mediated cell death, we examined the effects of coexposure of the glioma cells to C2-ceramide and CD95L. There were substantial increases in cytotoxicity after coexposure to ceramide and CD95L compared with exposure to either agent alone. To differentiate whether enhanced cell death in response to C2-ceramide and CD95L was additive or synergistic, we employed the fractional product method. ${ }^{24}$ Here, the effect of two independently acting agents is defined as the product of the unaffected fractions after treatment with either drug alone $\left[f_{u}(1,2)=f_{u}(1) \times f_{u}(2)\right]$. This formula allows to calculate the predicted effect of co-treatment, based on the assumption that two agents do not interact or cooperate in inducing their effects. If the relative percentage of surviving cells is significantly below the predicted effect after cotreatment with the two drugs, then synergy is postulated. Synergy was observed in both cell lines at various combinations of different concentrations of C2-ceramide and CD95L (Figure 3). Similar synergistic interactions between C2-ceramide and CD95L were observed in LN-229 and LN308 cells (data not shown). To demonstrate that the major mode of synergistically induced cell death was apoptosis, we measured DNA fragmentation in LN-229 glioma cells after treatment with C2-ceramide, CD95L or both. In accordance with the cytotoxicity rates shown in Figure 3, synergistic effects (defined as difference between observed 

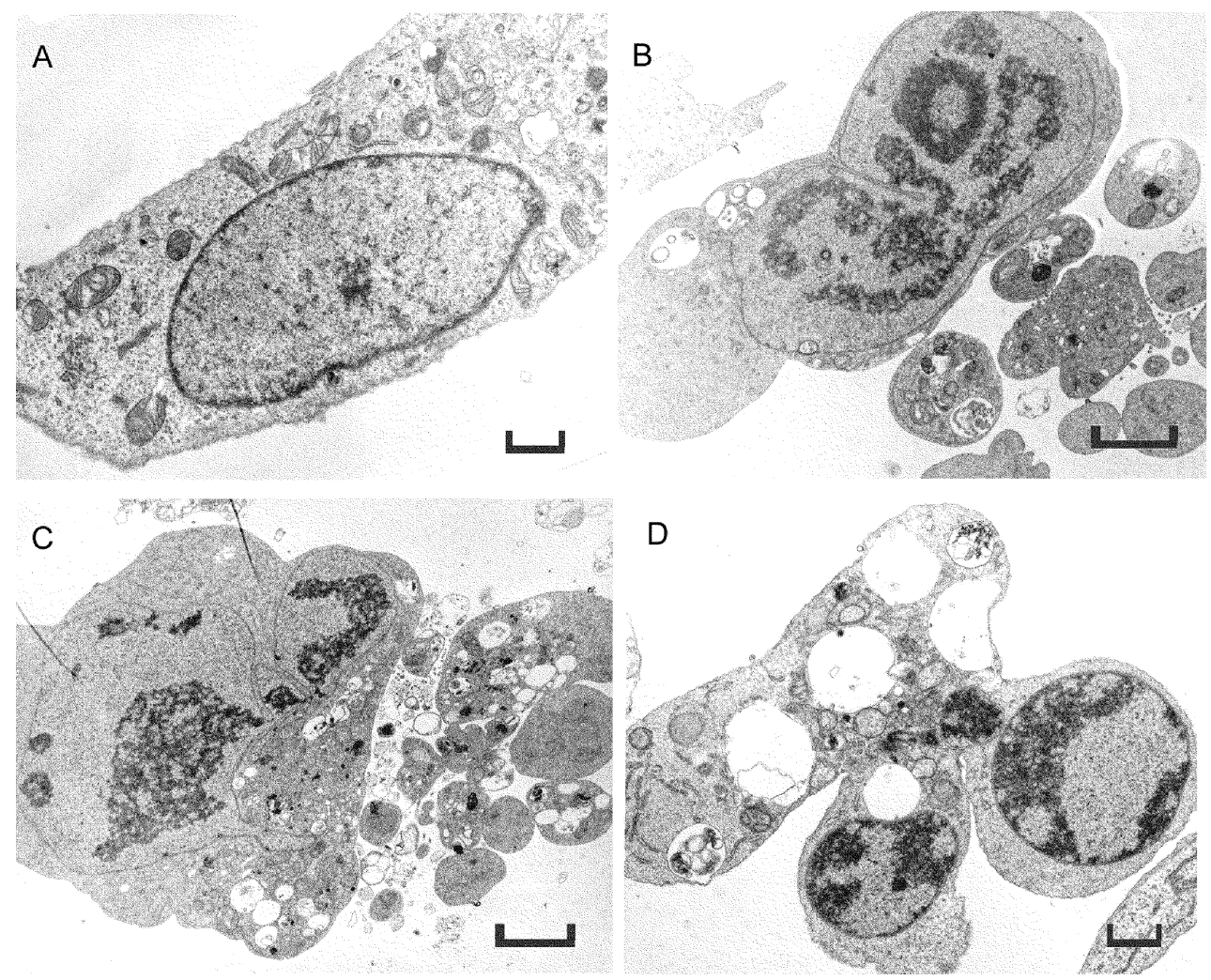

Figure 2 Morphological features of C2-ceramide-induced cell death in $\mathrm{LN}-18$ cells. Electron micrographs from LN-18 glioma cells treated by $\mathrm{C} 2$-ceramide $(50 \mu \mathrm{M}$; $8 \mathrm{~h}$; bar: $2 \mu \mathrm{m}$ ) (B), C2-ceramide plus CD95L (bar: $2 \mu \mathrm{m})(\mathbf{C})$, or CD95L alone $(40 \mathrm{U} / \mathrm{ml} ; 8 \mathrm{~h}$; bar: $1 \mu \mathrm{m})(\mathbf{D})$, show cytoplasmic blebbing and/or vacuolization, and nuclear and chromatin condensation. Untreated control cells (bar: $1 \mu \mathrm{m})(\mathbf{A})$ did not reveal this specific apoptotic phenotype

effects and calculated predicted effects) ranging between 10 and $25 \%$ were observed (data not shown). Using this assay, no DNA fragmentation was observed after treatment of cells with C2-ceramide alone $(50 \mu \mathrm{M})$ for $8 \mathrm{~h}$ or $16 \mathrm{~h}$ (data not shown).

\section{C2-ceramide kills glioma cells independently of zVAD-fmk-sensitive caspase activation, but enhances CD95L-evoked DEVD-amc-cleaving caspase activity}

To examine the role of caspase activation in the apoptosis of human malignant glioma cells induced by $\mathrm{C} 2$-ceramide alone or by co-treatment with $\mathrm{C} 2$-ceramide and CD95L, we treated LN-18 and T98G cells with C2-ceramide or CD95L in the presence of a broad spectrum caspase inhibitor, zVAD-fmk. Figure 4A shows that zVAD-fmk abrogated CD95L-induced apoptosis, but had no effect on C2-ceramide-induced apoptosis. Next, we were interested in the effects of C2ceramide on CD95L-mediated caspase activation. Therefore, we examined whether triggering of caspase 3-like protease activity by CD95L was augmented in glioma cells coexposed to $\mathrm{CD} 95 \mathrm{~L}$ and $\mathrm{C2}$-ceramide. Figure $4 \mathrm{~B}$ shows that treatment with CD95L induced substantial DEVD-amc-cleaving caspase activity in LN-18 and T98G glioma cells and that this activity was significantly enhanced by coincubation with
CD95L and C2-ceramide for $6 \mathrm{~h}$. No significant change in DEVD-amc-cleaving caspase activity was detected in glioma cells treated with $\mathrm{C} 2$-ceramide alone. Importantly, ceramide was used in the same concentration $(50 \mu \mathrm{M})$ that induced substantial cytotoxicity in these cell lines at $24 \mathrm{~h}$ (see Figure 1). Note that a value of 1 in Figure $4 B$ indicates the absence of a change of caspase activity and that there was also no increase in caspase activity in response to $\mathrm{C} 2$-ceramide alone at later time points (12 and $24 \mathrm{~h}$ ) (data not shown).

\section{C2-ceramide augments CD95L-induced cleavage of caspase 3, 8 and 9 and PARP and CD95L-induced cytochrome $c$ release from mitochondria}

Prompted by the finding that DEVD-amc-cleaving caspase activity upon CD95 ligation was potentiated by C2-ceramide (Figure 4B), we determined whether C2-ceramide coincubation would also lead to enhanced caspase processing as determined by immunoblot analysis. Figure $5 \mathrm{~A}, \mathrm{~B}$ and $\mathrm{C}$ demonstrate that $\mathrm{C} 2$-ceramide alone, although used at cytotoxic concentrations $(50 \mu \mathrm{M})$, did not induce the cleavage of caspases 3,8 or 9 in glioma cells. In contrast, treatment of LN-18 and T98G glioma cells with CD95L resulted in the cleavage of all three caspases examined. The proteolytic subunits of cleaved caspases are 
A

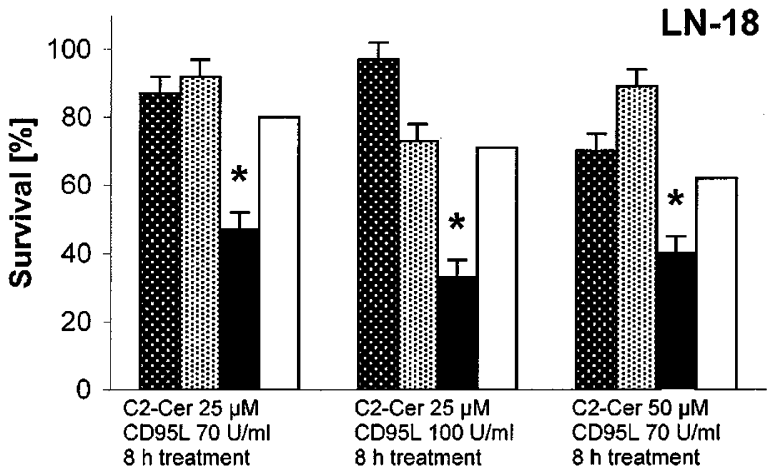

B

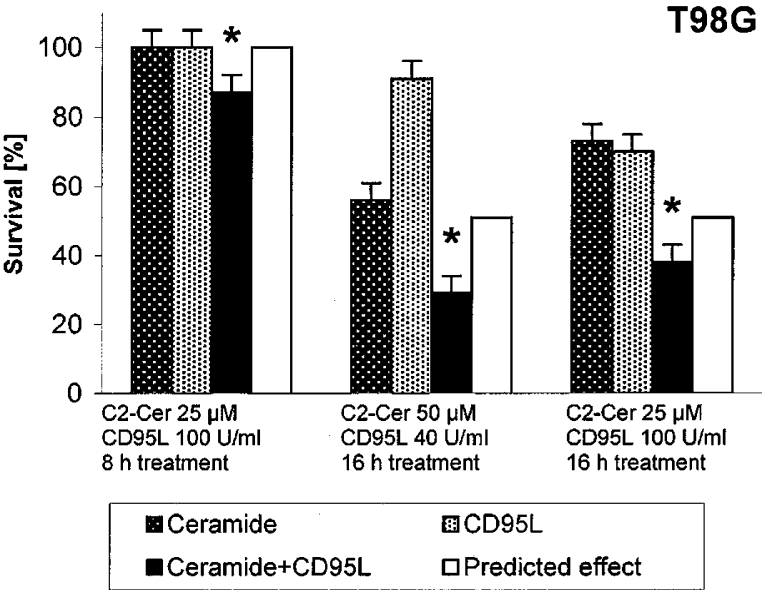

Figure 3 Synergistic effects of C2-ceramide and CD95L on human malignant glioma cells. LN-18 (A) or T98G (B) cells were exposed to C2-ceramide (25 or $50 \mu \mathrm{M})$ and CD95L $(40,70$ or $100 \mathrm{U} / \mathrm{ml})$ for 8 or $16 \mathrm{~h}$. Synergy was assessed by comparing predicted effect (open bars) with observed effect (black bars) of cotreatment according to the fractional product method. Whenever the open bars exceed the black bars, synergy is proven at the given effect level. Data are expressed as mean and S.D. of survival $\left(n=3,{ }^{*} P<0.05\right.$, $t$-test, observed effect compared with predicted effect)

the $17 \mathrm{kDa}$ fragment of caspase 3 , the $43 \mathrm{kDa}$ and $18 \mathrm{kDa}$ fragments of caspase 8 and the $35 \mathrm{kDa}$ fragment of caspase 9. In accordance with the fluorimetric findings, CD95-mediated cleavage of caspases 3,8 and 9 in the glioma cells was significantly enhanced after co-treatment with CD95L and C2-ceramide in both cell lines. Similarly, PARP cleavage was not induced by treatment with C2ceramide alone, but significantly enhanced by coexposure of glioma cells to CD95L and C2-ceramide compared with treatment with CD95L alone (Figure 5D). The PARP cleavage product migrates as a $85 \mathrm{kD}$ fragment. DNA fragmentation factor (DFF45), another caspase substrate, revealed a similar pattern of enhanced cleavage after treatment of cells with C2-ceramide and CD95L (data not shown). Further, mitochondrial cytochrome $c$ release, an important positive feedback pathway for caspase activation during apoptosis, was not promoted by $\mathrm{C} 2$-ceramide alone in either cell line, but was strongly enhanced by C2ceramide in CD95L-treated cells compared with cells exposed to CD95L alone (Figure 5E).

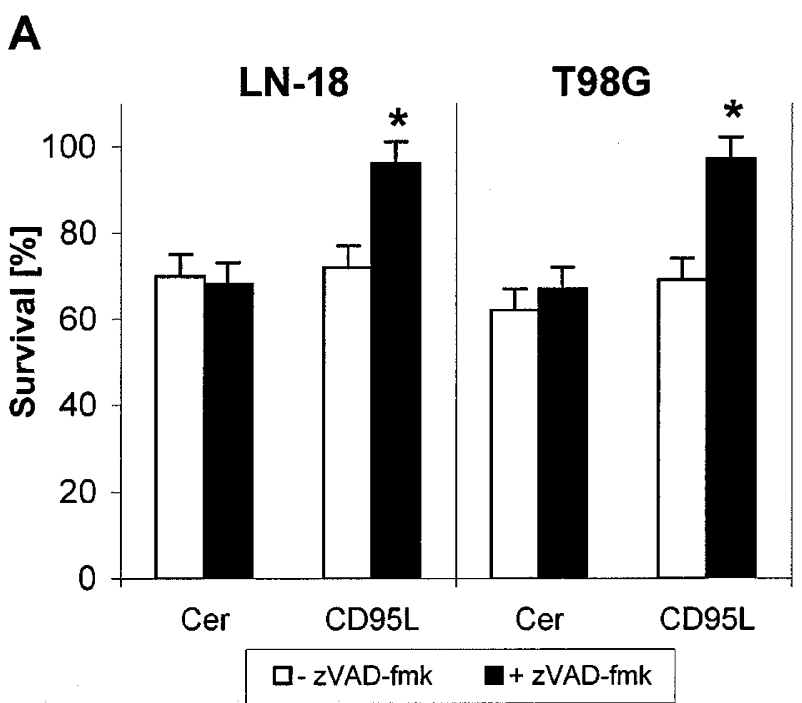

B

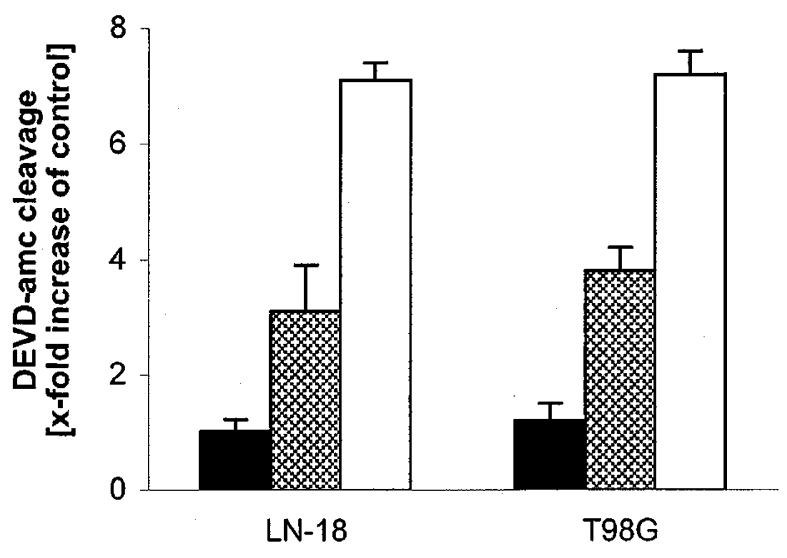

Ceramide OCD95L $\quad$ 口Ceramide+CD95L

Figure 4 Ceramide cytotoxicity is not blocked by a broad spectrum caspase inhibitor, but CD95L-induced DEVD-amc cleavage is potentiated by C2ceramide. (A) LN-18 or T98G cells were exposed to C2-ceramide (Cer, $50 \mu \mathrm{M})$ or CD95L (LN-18, $25 \mathrm{U} / \mathrm{ml}$; T98G, $100 \mathrm{U} / \mathrm{ml})$ for $16 \mathrm{~h}$ in the absence or presence of ZVAD-fmk $(100 \mu \mathrm{M})$ (mean + S.D., $n=3,{ }^{*} P<0.05, t$-test). B. LN-18 or T98G cells were treated with C2-ceramide $(50 \mu \mathrm{M}), \mathrm{CD} 95 \mathrm{~L}(30 \mathrm{U} / \mathrm{ml})$ or both for $4 \mathrm{~h}$. DEVD-amc-cleaving caspase activity was determined using a fluorometric assay (mean \pm S.D., $n=3$ )

\section{CD95 expression is not regulated by C2-ceramide, but enhanced CD95 expression sensitizes glioma cells to C2-ceramide-induced cell death}

One possible mechanism of synergy between $\mathrm{C} 2$-ceramide and CD95L would be a C2-ceramide-induced enhancement of CD95 expression in glioma cells, thereby facilitating CD95-dependent signaling. Flow cytometric determination of CD95 expression in LN-18 and T98G glioma cells that were untreated or exposed to $\mathrm{C} 2$-ceramide for 3 or $6 \mathrm{~h}$ revealed no significant change (Figure 6A). We also asked whether altering the level of CD95 expression would influence the 


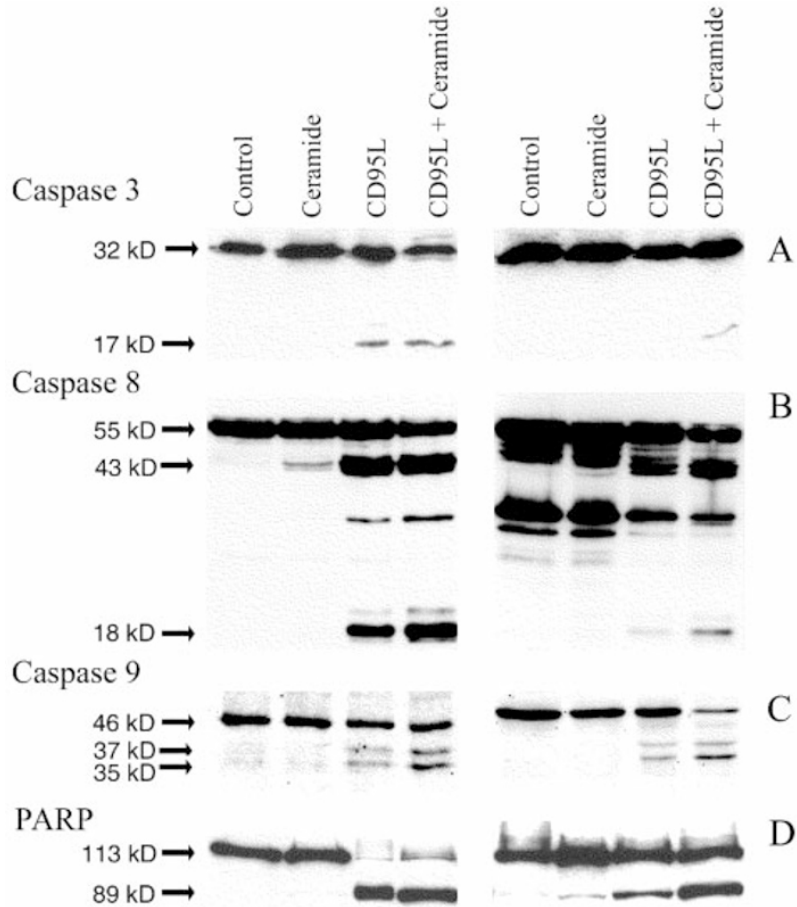

Cytochrome c

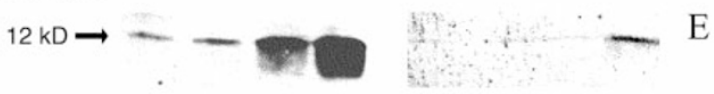

Figure 5 C2-ceramide potentiates CD95L-induced caspase processing, PARP cleavage and cytochrome $c$ release. $(A-C) L N-18$ or T98G cells were exposed to C2-ceramide $(50 \mu \mathrm{M}), \mathrm{CD} 95 \mathrm{~L}(60 \mathrm{U} / \mathrm{ml})$ or both for $6 \mathrm{~h}$. The processing of caspases 3,8 and 9 was analyzed by immunoblot. Activation of caspase 3 is reflected by the decrease of p32 and the occurence of p17. Activation of caspase 8 correlates with the occurrence of 43 and $18 \mathrm{kDa}$ proteolytic products. Activation of caspase 9 is reflected by the decrease of p46 and the occurrence of p35. (D) The cells were treated as in A-C. Cleavage of PARP resulted in the occurrence of a $89 \mathrm{kDa}$ proteolytic fragment. (E) Release of cytochrome $c$ from mitochondria was detected by immunoblot analysis of cytoplasmic proteins. Glioma cells were treated as in A-D

susceptibility of glioma cells to C2-ceramide. Thus, we transfected both cell lines with a CD95-encoding expression plasmid. ${ }^{25}$ Transfection resulted in strongly enhanced expression of CD95 at the cell surface (Figure 6B). Compared with neo control cells, CD95-transfected glioma cells were more sensitive to CD95L-induced apoptosis (Figure 6C,D). Curiously, LN-18 and T98G cells engineered to express high levels of CD95 also exhibited increased sensitivity to C2-ceramide. Further, when the cells were pretreated with a broad spectrum caspase inhibitor, zVADfmk, CD95L-induced apoptosis, but not C2-ceramidemediated cell death was inhibited, indicating that even enhanced killing of CD95-transfected cells by C2-ceramide was unaffected by inhibition of zVAD-fmk-sensitive caspases.

\section{Discussion}

The present study shows that several human malignant glioma cell lines are susceptible to cell death induced by exogenous C2-ceramide (Figure 1). As assessed by electron microscopy, cell death upon treatment with C2-ceramide exhibited some typical features of apoptosis although cytoplasmic apoptosis was more prominent than nuclear apoptosis (Figure 2). Importantly, coexposure of glioma cells to C2-ceramide and CD95L resulted in synergistic cytotoxicity (Figure 3), indicating a cross-talk between C2-ceramide and CD95 signaling. This synergy involved a ceramide-mediated increase (i) of the CD95L-induced processing of multiple caspases (Figure $5 \mathrm{~A}-\mathrm{C}$ ), (ii) of the cleavage of caspase substrates, PARP (Figure 5D) and DFF45 (not shown), and (iii) of cytochrome $c$ release from mitochondria into the cytosol (Figure 5E). C2-ceramide alone failed to induce either of these events of CD95-mediated apoptosis, even at cytotoxic concentrations, indicating that $\mathrm{C} 2$-ceramide signals a caspase-independent mode of apoptosis. That treatment of glioma cells with C2-ceramide alone did not result in DNA fragmentation is consistent with the failure to process DFF45 and indicates an important role of DFF45 in apoptosisassociated DNA fragmentation in glioma cells. Enforcing CD95 expression by gene transfer enhanced the sensitivity of glioma cells to C2-ceramide, and this sensitization mediated by elevated CD95 levels also required no caspase activation (Figure 6).

Taken together, we describe an interaction between C2ceramide and an as yet unknown target in the CD95 signaling cascade that leads to a facilitation of CD95dependent signaling elements although C2-ceramide alone is not capable of activating this signaling pathway in glioma cells. In response to an adequate trigger, e.g., cross-linking of CD95, the apoptotic signal is transduced much more efficiently than without that priming. Further, we delineate a C2-ceramide-dependent apoptotic cell death pathway in glioma cells that is not associated with caspase activation or release of cytochrome $c$ from mitochondria and is unaffected by the broad spectrum inhibitor, zVAD-fmk. Consistent with a proximal independence of CD95L-induced apoptosis and the C2-ceramidetriggered death pathway, LN-18 cells selected for resistance to cytotoxic cytokines do not acquire crossresistance to C2-ceramide (Figure 1). Curiously, this pathway was facilitated by enhanced CD95 expression but the sensitization was not reversed by caspase inhibition (Figure 6). Thus, in that pathway, there may either be activation of hitherto unknown caspases which are not sensitive to zVAD-fmk, or, alternatively, CD95 may provide non-caspase signaling events to confer enhanced sensitivity to C2-ceramide.

C2-ceramide and CD95 signaling pathways may also converge at the death inducing signaling complex (DISC). In that regard, Holler et al. ${ }^{26}$ demonstrated that CD95L induces a caspase-independent cell death pathway by recruiting receptor-interacting protein (RIP), in addition to FADD, to the DISC. It is tempting to speculate that the C2-ceramide-induced cell death pathway also employs RIP or another DISC-related unidentified protein. This could explain why ectopic expression of CD95 in glioma cells resulted in potentiation of C2-ceramide-induced, caspase-independent cell death. On the other hand, a ceramide-mediated modification of the DISC could also 
A

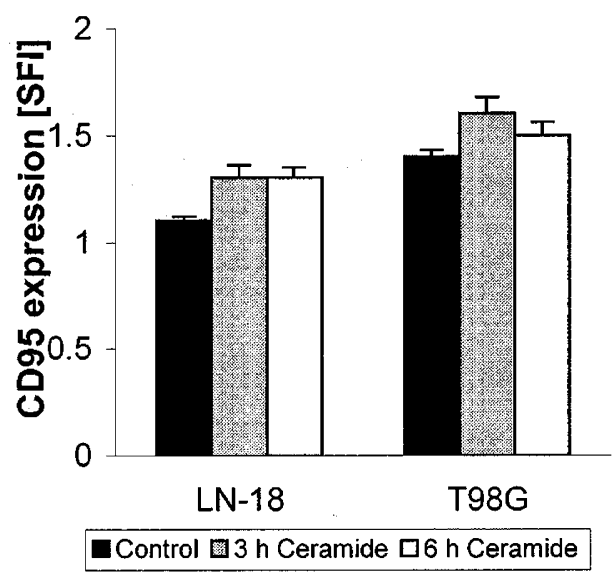

B

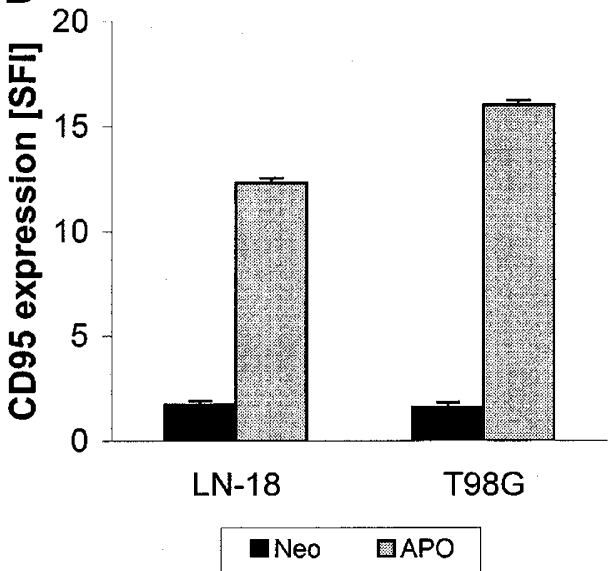

C

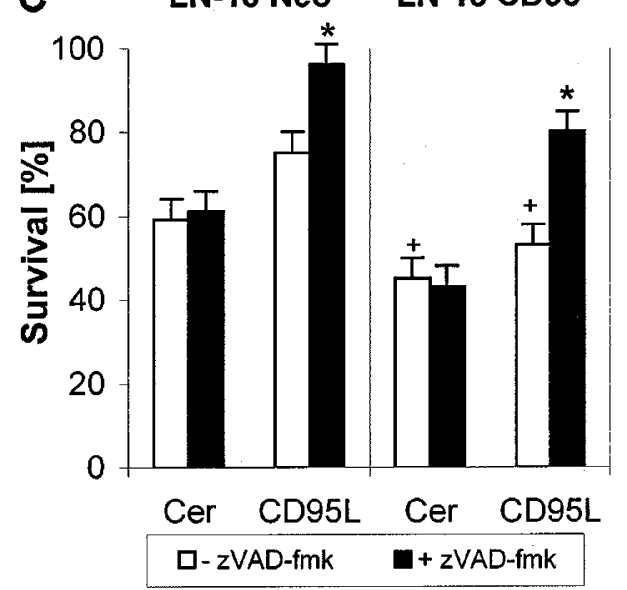

D

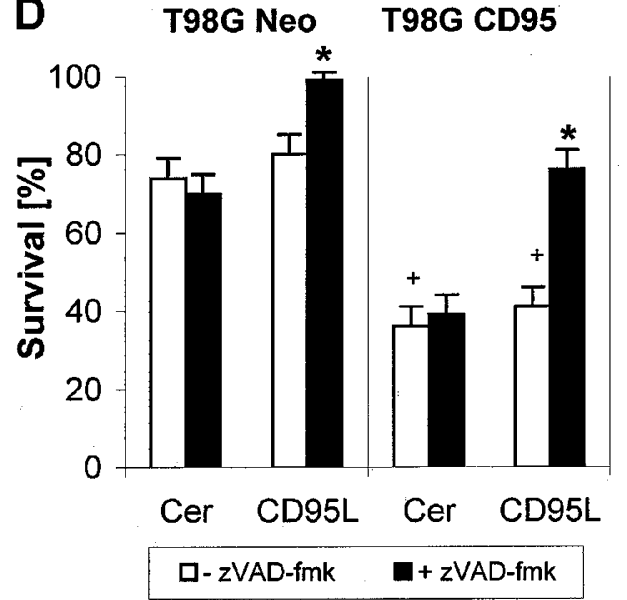

Figure 6 CD95 expression modulates glioma cell sensitivity to C2-ceramide. (A) LN-18 or T98G cells were either untreated or treated with $\mathrm{C} 2$-ceramide (50 $\mu \mathrm{M})$ for 3 or $6 \mathrm{~h}$. CD95 expression was assessed by flow cytometry and is depicted as SFI values (see Materials and Methods). The data are derived from one of two experiments with similar results. (B) Stable expression of CD95 at the cell surface of CD95-transfected LN-18 and T98G cells was ascertained by flow cytometry. (C,D) CD95-transfected or neo control cells of the lines LN-18 and T98G were exposed to C2-ceramide (50 $\mu \mathrm{M})$ or CD95L (LN-18, 25 U/ml; T98G, 100 U/ml) for $16 \mathrm{~h}$ in the absence or presence of the broad spectrum caspase inhibitor, zVAD-fmk, at $100 \mu \mathrm{M}$. Data are expressed as mean percentages and S.D. of survival $\left({ }^{+} P<0.05\right.$, $t$-test, difference between neo and CD95-transfected cells; ${ }^{*} P<0.05, t$-test, effect of $\left.z V A D-f m k\right)$

promote the classical CD95 signaling cascade. Other molecules that might be targeted by ceramide include caspases or inhibitors of caspases, JNK, ${ }^{10,12}$ a ceramideactivated proline-directed protein kinase, ${ }^{27}$ Raf- $\mathrm{K}^{28}$ and a phosphatase. $^{29}$ Furthermore, the C2-ceramide-triggered signaling cascade may interact with the arachidonic acid metabolites generated during CD95-mediated apoptosis in glioma cells, ${ }^{30}$ thereby potentiating proapoptotic signal events. A similar interaction has been described previously when C2-ceramide elicited a minor increase in secretory phospholipase A2 (sPLA2) and potentiated the induction of SPLA2 by TNF-alpha. ${ }^{31}$ However, it is important to bear in mind that short-chain C2-ceramide may not resemble the properties of endogenous ceramide too closely and might induce signaling events that are different from the signaling pathways triggered by endogenously produced longer-chain (C16) ceramides. $^{32}$
Previously we have reported that C2-ceramide-mediated apoptosis of glioma cells was inhibited by bcl-2. ${ }^{17}$ This raises the challenging question how bcl-2 acts to inhibit the ceramide-induced, caspase-independent cell death signaling. There is increasing evidence that bcl-2 interferes with mitochondria at the level of formation or detoxification of reactive oxygen species, calcium metabolism or the activity of apoptosis-inducing factor (AIF). These processes may be involved in caspase-independent pathways of cell death. For example, AIF is released from the mitochondrial interspace membrane and leads to disruption of the mitochondrial membrane potential in a zVAD-insensitive manner. ${ }^{33}$ Alternatively, bcl-2 could participate in the regulation of noncaspase proteases such as serin proteases, calpains or cathepsins. ${ }^{34}$ Interestingly, bcl-2 has also been demonstrated to inhibit NO-induced caspase-independent cell death. ${ }^{35}$ Therefore, a role of bcl-2 in the inhibition of caspase-independent cell death appears conceivable 
although the mechanisms of bcl-2-afforded protection from cell death as well as the modes of caspase-independent apoptosis have not been entirely understood.

\section{Materials and Methods}

\section{Cell culture, transfections and viability assay}

All human malignant glioma cell lines were kindly provided by Dr. $\mathrm{N}$ de Tribolet (Lausanne, Switzerland). The cells were maintained in DMEM containing $10 \%$ fetal calf serum, $2 \mathrm{mM}$ glutamine and antibiotics. LN18 and T98G glioma cells engineered to express enhanced levels of CD95 (APO-1) were obtained by lipofection with SuperFect (Qiagen, Hilden, Germany) using the human CD95 (APO-1)-containing BCMGS expression vector that harbours a neomycin (neo) resistance gene. ${ }^{25}$ Control cells were transfected with the BCMGS neo control plasmid. The cells were selected with neomycin $(500 \mu \mathrm{g} / \mathrm{ml})$, starting $48 \mathrm{~h}$ after transfection. All experiments were carried out with pooled transfectants to avoid cloning or selection artifacts.

Glioma cell viability was measured by crystal violet staining. Briefly, the cell culture medium was removed and surviving cells were stained with $0.5 \%$ crystal violet in $20 \%$ methanol for 20 min at room temperature. The plates were washed extensively under running tap water and air-dried. Optical density was measured in an ELISA reader at $550 \mathrm{~nm}$ wave length. Soluble CD95L was obtained from murine CD95L-transfected N2A neuroblastoma cells. ${ }^{36}$ Cycloheximide was purchased from Sigma (Deisenhofen, Germany). C2-ceramide was from Calbiochem (Bad Soden, Germany). Ac-DEVD-amc and zVADfmk were obtained from Bachem (Heidelberg, Germany).

\section{Determination of DNA fragmentation and chromatin condensation}

The cells were seeded in 6-well plates. DNA fragmentation was measured by quantitative DNA fluorometry after $24 \mathrm{~h}$ exposure to C2ceramide $(50 \mu \mathrm{M}), \mathrm{CD} 95 \mathrm{~L}(40 \mathrm{U} / \mathrm{ml})$ or both as outlined before. ${ }^{37}$ Nuclear morphology (chromatin condensation) was assessed by $4^{\prime}, 6-$ diamidine-2'-phenylindole dihydrochloride (DAPI) staining.

\section{Detection of CD95 expression}

For flow cytometric analysis of CD95 expression, glioma cells were detached from the culture dishes, harvested into ice-cold complete medium containing $10 \%$ fetal calf serum, centrifuged and resuspended in flow cytometry buffer ( $1 \%$ bovine serum albumin/PBS $/ 0.01 \%$ sodium azide). Subsequently UB2 anti-CD95 antibody $(1 \mu \mathrm{g} / \mathrm{ml})$ was added per sample $\left(10^{6}\right.$ cells) or, as a control, mouse $\operatorname{lgG}_{1}$. After washing, samples were labeled with sheep-anti-mouse IgG-FITC, washed, resuspended in $300 \mu \mathrm{l}$ PBS containing 1\% formaldehyde and stored light-protected at $4^{\circ} \mathrm{C}$ prior to analysis by a Becton Dickinson FACScalibur cytometer. The specific fluorescence index (SFI) was calculated as the ratio of the mean fluorescence values obtained with the specific CD95 antibody and the isotype control antibody. ${ }^{25}$

\section{Immunoblot analysis}

Soluble protein lysates were obtained from subconfluent glioma cell cultures. SDS-PAGE was performed as described. ${ }^{36}$ Caspase 8 antibody $\mathrm{C} 15$ (mouse monoclonal) was kindly provided by $\mathrm{Dr}$. $\mathrm{PH}$ Krammer (Heidelberg, Germany). Caspase 3 antibody (mouse monoclonal) was obtained from Transduction Laboratories (Lexington, KY, USA). Caspase 9 antibody was kindly provided by Dr. Y
Lazebnik (Cold Spring Harbor, NY, USA). ${ }^{38}$ PARP antibody was purchased from Boehringer (Mannheim, Germany). Cytochrome $c$ antibody was from PharMingen (San Diego, CA, USA). The secondary antibodies, protein $A$ and anti-mouse $\operatorname{lgG}$, were purchased from Amersham (Braunschweig, Germany). Enhanced chemiluminescence (ECL, Amersham) was used for detection.

\section{Electron microscopy}

Ultrastructural analysis of C2-ceramide- and CD95L-induced cell death at $8 \mathrm{~h}$ after treatment as indicated was assessed by transmission electron microscopy as previously described. ${ }^{39}$

\section{Measurement of cytochrome $c$ release}

Glioma cells were exposed to C2-ceramide, washed with PBS and lysed for $5 \mathrm{~min}$ at $4^{\circ} \mathrm{C}$ with buffer containing $210 \mathrm{mM}$ D-mannitol, $70 \mathrm{mM}$ sucrose, $10 \mathrm{mM}$ HEPES, $200 \mu \mathrm{M}$ EGTA, $5 \mathrm{mM}$ succinate, $0.15 \% \mathrm{BSA}$ and $40 \mu \mathrm{g} / \mathrm{ml}$ digitonin. After lysis, the supernatant (cytosolic fraction) was centrifuged for $10 \mathrm{~min}$ at 13000 r.p.m. The supernatant was incubated with an equal volume of $10 \%$ trichloroacetic acid. The samples were kept at $-20^{\circ} \mathrm{C}$ for $30 \mathrm{~min}$ and then centrifuged for $10 \mathrm{~min}$ at 13000 r.p.m. The pellets were resuspended in Laemmli buffer and analyzed for cytochrome $c$ content by immunoblot analysis.

\section{Caspase 3-like enzymatic activity}

Assessment of caspase 3-like activity was performed as previously described. ${ }^{40}$ Briefly, the glioma cells were seeded in 96 -well plates (10 000 cells per well), allowed to attach for $24 \mathrm{~h}$ and exposed to C2ceramide for $6 \mathrm{~h}$. The cells were lysed in lysis buffer for $10 \mathrm{~min}$. Subsequently, the substrate, acetyl-Asp-Glu-Val-Asp-chloromethyl coumarine (Ac-DEVD-amc, $12.5 \mu \mathrm{M}$ ), was diluted in PBS and added to the lysates. After an incubation period for $30 \mathrm{~min}$ at $37^{\circ} \mathrm{C}$, DEVDamc-cleaving (caspase 3 -like) activity was measured using a CytoFluor 2350 Millipore fluorometer at $360 \mathrm{~nm}$ excitation and $480 \mathrm{~nm}$ emission wave lengths.

\section{Statistical analysis}

The significance of effects on viability in simple assays was assessed by $t$-test $(P=0.05)$. Synergy was assessed by the fractional product method. $^{24} \mathrm{~A}$ correlation between C2-ceramide sensitivity and sensitivity to CD95L or Apo2L/TRAIL was assessed by linear correlation analysis.

\section{Acknowledgements}

We thank Y Lazebnik (Cold Spring Harbor, NY, USA) for caspase 9 antibody and $\mathrm{PH}$ Krammer (Heidelberg, Germany) for caspase 8 antibody. This study was supported by the German Cancer Council (Deutsche Krebshilfe) (10-1287-We 2).

\section{References}

1. Kolesnick RN and Krönke M (1998) Regulation of ceramide production and apoptosis. Annu. Rev. Physiol. 60: 643-665

2. Kolesnick RN, Haimovitz-Friedman A and Fuks Z (1994) The sphingomyelin signal transduction pathway mediates apoptosis for tumor necrosis factor, Fas, and ionizing radiation. Biochem. Cell Biol. 72: 471-474 
3. Ramachandran CK, Murray DK and Nelson DH (1990) Dexamethasone increases neutral sphingomyelinase activity and sphingosine levels in 3T3-L1 fibroblasts. Biochem. Biophys. Res. Commun. 167: 607-613

4. Kim MY, Linardic C, Obeid L and Hannun Y (1991) Identification of sphingomyelin turnover as an effector mechanism for the action of tumor necrosis factor alpha and gamma-interferon. Specific role in cell differentiation. J. Biol. Chem. 266: 484-489

5. Cifone MG, Roncaioli P, De MR, Camarda G, Santoni A, Ruberti G and Testi R (1995) Multiple pathways originate at the Fas/APO-1 (CD95) receptor: sequential involvement of phosphatidylcholine-specific phospholipase $C$ and acidic sphingomyelinase in the propagation of the apoptotic signal. EMBO J. 14 $5859-5868$

6. Gulbins E, Bissonnette R, Mahboubi A, Martin S, Nishioka W, Brunner T, Baier G Baier-Bitterlich G, Byrd C and Lang F (1995) FAS-induced apoptosis is mediated via a ceramide-initiated RAS signalling pathway. Immunity 2: 341-351

7. Tepper AD, Cock JG, de Vries E, Borst J and van Blitterswijk WJ (1997) CD95/ Fas-induced ceramide formation proceeds with slow kinetics and is not blocked by caspase-3/CPP32 inhibition. J. Biol. Chem. 272: 24308-24312

8. Hannun YA (1994) The sphingomyelin cycle and the second messenger function of ceramide. J. Biol. Chem. 269: 3125-3128

9. Grullich C, Sullards CA, Fuks Z, Merrill AH and Kolesnick R (2000) CD95 (Fas/ APO-1) signals ceramide generation independent of the effector stage of apoptosis. J. Biol. Chem. 275: 8650-8656

10. Westwick JK, Bielawska AE, Dbaibo G, Hannun YA and Brenner DA (1995) Ceramide activates the stress-activated protein kinases. J. Biol. Chem. 270: 22689-22692

11. Yao B, Zhang Y, Delikat S, Mathias S, Basu S and Kolesnick R (1995) Phosphorylation of Raf by ceramide-activated protein kinase. Nature 378: 307 310

12. Verheij M, Bose R, Lin XH, Yao B, Jarvis WD, Grant S, Birrer MJ, Szabo E, Zon LI, Kyriakis JM, Haimovitz-Friedman A, Fuks Z and Kolesnick RN (1996) Requirement for ceramide-initiated SAPK/JNK signalling in stress-induced apoptosis. Nature 380: 75-79

13. Zhang Y, Yao B, Delikat S, Bayoumy S, Lin XH, Basu S, McGinley M, Chan-Hu PY, Lichenstein Hand KolesnickR (1997) Kinase suppressor of Ras is ceramideactivated protein kinase. Cell 89: 63-72

14. Mathias S, Dressler KA and Kolesnick RN (1991) Characterization of a ceramide-activated protein kinase: stimulation by tumor necrosis factor alpha. Proc. Natl. Acad. Sci. USA 88: 10009-10013

15. Wolff RA, Dobrowsky RT, Bielawska A, Obeid LM and Hannun YA (1994) Role of ceramide-activated protein phosphatase in ceramide-mediated signal transduction. J. Biol. Chem. 269: 19605-19609

16. Mizushima N, Koike R, Kohsaka H, Kushi Y, Handa S, Yagita H and Miyasaka N (1996) Ceramide induces apoptosis via CPP32 activation. FEBS Lett. 395: 267 271

17. Wagenknecht B, Schulz JB, Gulbins E and Weller M (1998) Crm-A, bcl-2 and NDGA inhibit CD95L-induced apoptosis of malignant glioma cells at the level of caspase 8 processing. Cell Death Differ. 5: 894-900

18. Yount GL, Levine KS, Kuriyama H, Haas-Kogan DA and Israel MA (1999) Fas (APO-1/CD95) signaling pathway is intact in radioresistent human glioma cells. Cancer Res. 59: 1362-1365

19. Weller M, Frei K, Groscurth P, Krammer PH, Yonekawa Y and Fontana A (1994) Anti-Fas/APO-1 antibody-mediated apoptosis of cultured human glioma cells. Induction and modulation of sensitivity by cytokines. J. Clin. Invest. 94: 954-964

20. Weller M, Malipiero U, Aguzzi A, Reed JC and Fontana A (1995) Protooncogene bcl-2 gene transfer abrogates Fas/APO-1 antibody-mediated apoptosis of human malignant glioma cells and confers resistance to chemotherapeutic drugs and therapeutic irradiation. J. Clin. Invest. 95: 2633-2643

21. RiegerJ, Naumann U, Glaser T, Ashkenazi A and WellerM (1998)APO2 ligand:a novel lethal weapon against malignant glioma?. FEBS Lett. 427: 124-128

22. Weller M, Rieger J, Grimmel C, Van Meir EG, De Tribolet N, Krajewski S, Reed $\mathrm{JC}$, von Deimling A and Dichgans $\mathrm{J}$ (1998) Predicting chemoresistance in human malignant glioma cells: the role of molecular genetic analyses. Int. J. Cancer 79 : $640-644$
23. Glaser T, Wagenknecht B, Groscurth $P$, Krammer PH and Weller M (1999) Death ligand/receptor-independent caspase activation mediates drug-induced cytotoxic cell death in human malignant glioma cells. Oncogene 18: 5044-5053

24. Webb JL (1963) Effect of more than one inhibitor. In: Enzyme and metabolic inhibitors. Academic press. New York. Vol. 1, pp 66-79 and 487-512

25. Weller M, Malipiero U, Rensing EhI A, Barr PJ and Fontana A (1995) Fas/APO-1 gene transfer for human malignant glioma. Cancer Res. 55: 2936-2944

26. Holler N, Zaru R, Micheau O, Thome M, Attinger A, Valitutti S, Bodmer JL, Schneider P, Seed B and Tschopp J (2000) Fas triggers an alternative, caspase8-independent cell death pathway using the kinase RIP as effector molecule. Nat. Immunol. 1: 489-495

27. Joseph CK, Byun HS, Bittman R and Kolesnick RN (1993) Substrate recognition by ceramide-activated protein kinase. Evidence that kinase activity is prolinedirected. J. Biol. Chem. 268: 20002-20006

28. Huwiler A, Brunner J, Hummel R, Vervoordeldonk M, Stabel S, van den Bosch H and Pfeilschifter J (1996) Ceramide-binding and activation defines protein kinase $c$-Raf as a ceramide-activated protein kinase. Proc. Natl. Acad. Sci. USA 93: 6959-6963

29. Dobrowsky RT, Kamibayashi C, Mumby MC and Hannun YA (1993) Ceramide activates heterotrimeric protein phosphatase 2A. J. Biol. Chem. 268: 1552315530

30. Wagenknecht B, Gulbins E, Lang F, Dichgans J and Weller M (1997) Lipoxygenase inhibitors block CD95 ligand-mediated apoptosis of human malignant glioma cells. FEBS Lett. 409: 17-23

31. Tong W, Shah D, Xu J, Diehl JA, Hans A, Hannink M and Sun GY (1999) Involvement of lipid mediators on cytokine signaling and induction of secretory phospholipase A2 in immortalized astrocytes (DITNC). J. Mol. Neurosci. 12: 89 99

32. Kolesnick RN, Goni FM and Alonso A (2000) Compartmentalization of ceramide signaling: physical foundations and biological effects. J. Cell. Physiol. 184:285300

33. Susin SA, Lorenzo HK, Zamzami N, Marzo I, Snow BE, Brothers GM, Mangion J, Jacotot E, Costantini P, Loeffler M, Larochette N, Goodlett DR, Aebersold R, Siderovski DP, Penninger JM and Kroemer G (1999) Molecular characterization of mitochondrial apoptosis-inducing factor. Nature 397: 441-446

34. Borner $C$ and Monney L (1999) Apoptosis without caspases: an inefficient molecular guillotine?. Cell Death Differ. 6: 497-507

35. Okuno S, Shimizu S, Ito T, Nomura M, Hamada E, Tsujimoto $Y$ and Matsuda $H$ (1998) Bcl-2 prevents caspase-independent cell death. J. Biol. Chem. 273: $34272-34277$

36. Roth W, Fontana A, Trepel M, Reed JC, Dichgans J and Weller M (1997) Immunochemotherapy of malignant glioma: synergistic activity of CD95 ligand and chemotherapeutics. Cancer Immunol. Immunother. 44: 55-63

37. Weller M, Trepel M, Grimmel C, Schabet M, Bremen D, Krajewski S and Reed JC (1997) Hypericin-induced apoptosis of human malignant glioma cells is lightdependent, independent of bcl-2 expression, and does not require wild-type p53. Neurol. Res. 19: 459-470

38. Fearnhead HO, Rodriguez J, Govek EE, Guo W, Kobayashi R, Hannon G and Lazebnik YA (1998) Oncogene-dependent apoptosis is mediated by caspase-9. Proc. Natl. Acad. Sci. USA 95: 13664-13669

39. Hermisson M, Wagenknecht B, Wolburg H, Glaser T, Dichgans $\mathrm{J}$ and Weller $\mathrm{M}$ (2000) Sensitization to CD95 ligand-induced apoptosis in human glioma cells by hyperthermia involves enhanced cytochrome c release. Oncogene 19: 23382345

40. Wagenknecht B, Glaser T, Naumann U, Kügler S, Isenmann S, Bähr M, Korneluk R, Liston P and Weller M (1999) Expression and biological activity of X-linked inhibitor of apoptosis (XIAP) in human malignant glioma. Cell Death Differ. 6: $370-376$ 